\title{
Issue in Implementing Customer Operations Performance Center (COPC)
}

\author{
Yingyu $\mathrm{Xu}^{1}$, Xinyuan $\mathrm{Xi}^{2}$, Yuki Todo ${ }^{3 *}$ \\ ${ }^{1}$ China Soft International Technology Service Ltd., Shanghai, China; ${ }^{2}$ LeLe Mother’s Maternal Store Ltd., Shanghai, China; \\ ${ }^{3}$ Department of Electrical and Computer Engineering, Kanazawa University, Kanazawa, Japan. \\ Email: *yktodo@se.kanazawa-u.ac.jp
}

Received June $10^{\text {th }}$, 2013; revised July $12^{\text {th }}, 2013$; accepted July $19^{\text {th }}, 2013$

Copyright (C) 2013 Yingyu Xu et al. This is an open access article distributed under the Creative Commons Attribution License, which permits unrestricted use, distribution, and reproduction in any medium, provided the original work is properly cited.

\begin{abstract}
Customer Operations Performance Center Inc (COPC) is the world's leading authority on Contact Center Operations Management. The COPC 2000 Standard is a comprehensive operating model for Contact Centre Operations. It is a world-wide benchmark and certification for contact centers. As well as an overall performance management system, COPC is designed to reduce costs, increase revenue, and improve service, quality and customer satisfaction. However, many COPC implementation projects failed. In this study, we first review the process of implementing COPC. Then, we identify major barriers in implementing COPC. Organizations should take proper measures in overcoming these barriers to ensure successful implementation of COPC.
\end{abstract}

Keywords: COPC; IT Management

\section{Introduction}

COPC- $2000^{\circledR}$ is developed by the purchaser, the providers and operation management executive of customercentric service in 1996. Dissatisfied with current operating performance and the lack of operating principles, these persons fill the gap by the joint efforts, and promote improvements of the industry. The standard describes the performance management methodology must be developed by the provider, evaluation indicators which the provider must evaluate the effectiveness and efficiency of their method are defined. It is the provider of a sustainable performance management framework. The COPC- $2000^{\circledR}$ framework links provider's customer-centric performance objectives of its business processes, management and maintenance processes, and staffs to maintain these processes together. These goals, processes and people in turn with the direction of the declaration and to promote and maintain these aspects of the strategy linked. This organic unity ensures that the customer-centric philosophy and efficiency continue to promote the development of the performance,behavior and direction [1].

The COPC standard does not set specific performance targets must be met for each call center. It creates practical operating requirements of the indicators and criteria

\footnotetext{
*Corresponding author.
}

designed to promote the consistently high standard of customer and employee satisfaction. This allows organizations or departments pursuing certification are called to develop targets that make sense in the context of their own operation and the parameters specific to their industry. COPC assess these goals, based on best practices and customer expectations, and provide guidance. However, some factors that erode the value of IT services generated are observed, and become the barriers to the success of COPC [2].

We first offer a review of COPC, and present the fad of adoption of COPC, then, acquire the major barriers to succeeding in COPC by reviewing literature and in-depth interviews with COPC practitioner and professional. Finally, some suggestions and managerial implications are discussed.

\section{Literature Review}

\subsection{COPC Performance Management System}

COPC-2000 Performance Management System is developed by COPC Inc. and it provides a benchmark for the buyer. COPC certification provides defined method, measured metrics and the results highlight qualified suppliers. To become qualified, COPC Inc. provides consulting services, benchmarking services, training, installation and 
design process to help enterprises to continuously measure the performance of the contact center [3].

In order to fulfill the goal of COPC, there are four significant dimensions should be considered proactively. The first dimension is leadership and planning, which are the major role in COPC framework, which requires annual verification of employee skill sets regularly. The second dimension is Processes, which requires held business meetings and business plans that comply with the COPC Standard. The third dimension is People which require semi-annual process audits. The last dimension is Performance Measurement which requires annual tracking and management of staff attrition.

\subsection{COPC Goal}

The COPC ${ }^{\circledR}$ Performance Management System is a set of management practices, key metrics or measurements and training for customer-centric service operations designed to:

- Improve customer satisfaction through improved service and quality;

- Increase revenue (for centers that are revenue driven);

- Reduce the cost of providing excellent service (Figure 1 shows COPC benefits clearly) [4].

\subsection{The Pervasive Adoption of COPC}

Since its introduction, over 120 locations in 16 countries have become certified to the Standard. The list includes firms in e-commerce, computer hardware and software, financial services, healthcare, marketing support services, A/R management, and collection services. Organizations such as Levi Strauss, Blue Cross Blue Shield, Bell Canada, Convergys and ClientLogic are among those either using or certified to the Standard. Also some qualitative benefits were recognized after implementing COPC:

1) Improved customer satisfaction;

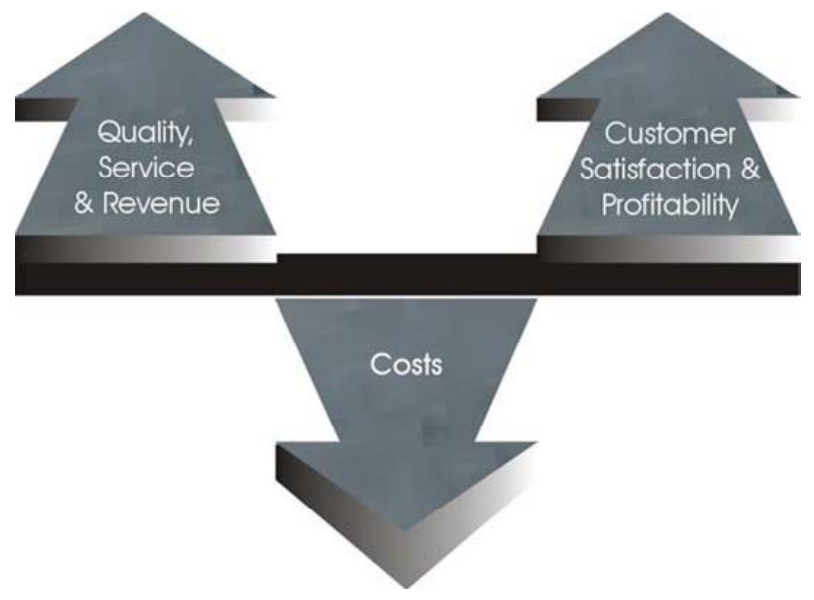

Figure 1. Shows the COPC benefits.
2) Improved morale of service delivery and recipient staff;

3) Reduced staff turnover;

4) Lower costs of training, especially as the COPC standard become widely adopted;

5) Improved systems/applications availability;

6) Improved IT employee productivity;

7) Reduced cost/incident;

8) Reduced hidden costs that traditionally;

9) Better asset utilization.

\section{Barriers to the Success of COPC}

While implementing COPC, we may encounter many issues. For example, these quality certification system implemented in the call centers within 100 seats has great difficulties, it takes a lot of energy, material and human resources, fell into the red tape of various quality documents. The quality management system is not suitable for the company finally and the quality management will become a mere formality. In addition, regardless of the cost center-based call center established in, or based on the profit center to set up the call center, there are checks and balances between costs and customer satisfaction [5], companies try to find a solution which can settle up this embarrassing problem of effective quality management system or programs. For profit call center, quality management department needs to be given more profit indicators responsibility, its responsibilities tends to cope with the operations department to complete profit targets; Quality control department's duties will be set for the call center cost control management, through analyzing, controlling, and improving call center's metrics by the quality control department, it will achieve the balance between cost and service levels and development indicators of the call center [6-10].

We conducted in-depth interviews with industrial practitioners in two companies, one company is the PC vendor, and another is the IT world-class company. The interviews consisted of interviewing with leader of the certification team, chief information officers, and the process managers.

We adopt four-dimension lens (leadership and planning, processes, people, performance measurement) from COPC discipline and the detailed results are discovered below in Table 1.

\section{Discussion}

Present study suggests that there are several barriers which may affect the COPC implementation. First the COPC 2000 is customized to hope to achieve world-class level of service enterprises, adhere to high standards and strict requirements from the outset. Higher performance standards hinder the expansion of the portion of the call 
Table 1. Detailed results discovered from four-dimension lens. Source: Constructed by the author.

\begin{tabular}{ccc}
\hline Stages & Dimensions & Major Barriers \\
\hline & leadership and planning & Resistance to change \\
$\begin{array}{c}\text { Valuation } \\
\text { Stage }\end{array}$ & processes & Misalignment between process \\
& People & Lack of commitment \\
& Performance & inappropriate measurement tool \\
Measurement & People & Insufficient team allocation \\
Stage & Organization & Complexity \\
\hline
\end{tabular}

center certification. On the other hand, COPC certification costs more expensive, which are relatively heavy burden for call centers. Also COPC certification cycle takes 9 - 12 months. It will bring some fluctuations to the call centers in daily work.

From our viewpoint, organizations that regard COPC as an opportunity to improve their performance and gain competitiveness should pay attention to those barriers, which can erode the value of implementation.

In the first phase, the organization should consider all four aspects. Manager had different skills and there are no established parameters to ensure a consistent crosssite management. The commitment barrier includes management of inadequate support and staff incomplete awareness. As a practitioner pointed out that, we have taken the bottom-up approach to carry out COPC, from awareness training. The obstacles relates to technology is inappropriate management tools, for example, many indicators were not in place or there were no targets, and the vendor does not investigate performance metric definitions and data integrity issues is also abundant. COPC takes a process-oriented approach, if the current process is rigid and cannot be justified, it will limit the performance. From the organization view, resistance to change may lead to a negative view, including increasing overload, lack of knowledge. These obstacles will reduce the value of COPC can produce. Another organization obstacle is lack of resources. IT investment needs the support from both of financial and human resources.

During the conversion phase, the organizations have implemented COPC and the previous process has been redesigned. If there is no appointed project manager, the project team does not have enough distribution, and IT staff does not want to learn new skills, values cannot be fully realized. Another obstacle is the complexity in this stage of the organizational level. COPC project is much more complex than others, as it relates to an inter-departmental process and it requires more cooperation and communication.

\section{Conclusion}

As some major barriers to the successful implementation of COPC were described in detail, we recommend that the organization should first determine what kind of Barriers in the valuation and conversion stages. Secondly, take the initiative action to deal with them. For valuation stage, the action can include setting up commitment of COPC construction, the establishment of cultural change, to establish clear and achievable goals, re-design process, and acquire financial resources to support. For conversion phase, the action may involve the implementation of the training program or transaction monitoring program to improve the skills to deal with complex COPC projects, and the establishment of the team assigned to complete the goal. Only when the initiative actions correctly identify and remove these barriers, the implementation of COPC can fully achieve the desired value.

\section{REFERENCES}

[1] A. Steinhart and R. M. Tharnish, “COPC-2000 ${ }^{\circledR}$ : Pursuing Excellence through Standards Certification.”

[2] Wikipedia, the Free Encyclopedia. http://en.wikipedia.org/wiki/COPC_Inc

[3] Contact Centers Performance Management Systems-A Latin American Perspective on COPC. http://www.frost.com/prod/servlet/market-insight-print.pa g?docid=140096623

[4] A. Sergeant and S. Frenkel, "When Do Customer Contact Employees Satisfy Customers," Journal of Service Research, Vol. 3, No. 1, 2000, pp. 18-34. doi:10.1177/109467050031002

[5] A. M. Susskind, C. P. Borchgrecink and K. Michele Kacmar, "Customer Service Employees' Behavior Intentions and Attitudes: An Examination of Construct Validity and a Path Model," Hospitality Management, Vol. 19, No. 1, 2000, pp. 53-77. doi:10.1016/S0278-4319(99)00030-4

[6] L. Gronholdt, A. Martensen and K. Kristensen, "The Relationship between Customer Satisfaction and Loyalty: Cross-Industry Differences,” Total Quality Management, Vol. 11, No. 4, 2000, pp. 509-514. doi:10.1080/09544120050007823

[7] M. Bruhn and M. A. Grund, "Theory Development and Implementation of National Customer Satisfaction Indices: The Swiss Index of Customer Satisfaction (SWICS),” Total Quality Management, Vol. 11, No. 7, 2000, pp. 1017-1028. doi:10.1080/09544120050135542

[8] C. M. Cassel, P. Hackl and A. H. Westlund, "On Measurement of Intangible Assets: A Study of Robustness of Partial Least Squares,” Total Quality Management, Vol. 11, No. 7, 2000, pp. 897-907. doi:10.1080/09544120050135443

[9] D. R. Allen and T. R. Rao, “Analysis of Customer Satisfaction Data,” 2000.

[10] J. Disney, "Customer Satisfaction and Loyalty: The Critical Element of Service Quality,” Total Quality Management, Vol. 10, No. 4-5, 1999, pp. 491-497. 